\title{
LOS CORTOMETRAJES DE ANIMACIÓN COMO HERRAMIENTA DIDÁCTICA PARA TRABAJAR LA EDUCACIÓN EN VALORES EN EDUCACIÓN INFANTIL
}

\author{
Animation short films as didactic tool to work education in values with young \\ children
}

Virginia Guichot-Reina

María Auxiliadora Merino Delgado

Fecha recepción: 10/06/2016

Fecha aceptación: 05/11/2016

RESUMEN: Educar en valores en la etapa de Infantil contribuye al proceso de desarrollo y construcción personal de niños y niñas. En las escuelas, una de las principales funciones del profesorado es que el alumnado interiorice los valores democráticos. Para que los docentes puedan contribuir a ello de manera óptima, no basta con el apoyo de una legislación que regule y favorezca dicho ámbito, sino que deben poseer una formación que les proporcione herramientas para un trabajo eficaz y satisfactorio dentro de las aulas. Desde hace algunos años, se plantean propuestas pedagógicas centradas en el desarrollo moral a partir del trabajo con ciertas películas que giran en torno a valores democráticos (Ruíz Rubio, 1994; Martínez-Salanova, 2003; Ambrós y Breu, 2007). En este artículo, presentamos una experiencia pedagógica, dentro de estos parámetros, realizada en el último curso de la etapa de educación infantil durante el año escolar 2014-2015 centrada en un cortometraje de animación, "El Puente". Hemos comprobado que el uso de estos recursos audiovisuales, acompañado de actividades que refuercen el aprendizaje de valores, es un elemento muy motivador para el alumnado y capaz de contribuir a modificar conductas en los más pequeños cara a fomentar una cultura de la paz.

PALABRAS CLAVE: Educación moral, educación preescolar, método audiovisual, cine, valor.

ABSTRACT: Education in values in the kindergarten contributes to the process of development and personal construction of young children. At schools, one of the main functions of teachers is that all the students internalize democratic values. It is not sufficient to have the support of legislation that regulates and encourages this area so that teachers would be able to tribute it by an optimal way. They must have a training that provides them with tools for effective and satisfactory classroom work. For some years now, pedagogical proposals have been proposed focusing on moral development based on work with certain short films that revolve around democratic values (Ruíz Rubio, 1994; Martínez-Salanova, 2003; Ambrós and Breu, 2007). We show an experience in the early childhood education (5 years-old students) during the academic year 2014-2015, based on a short film, "The Bridge". As conclusion, the use of audiovisual productions, connected to suitable activities, is a very motivating factor for young children. It is able to contribute to modify behaviors in young children directed towards a culture of peace.

KEYWORDS: Moral Education, Education in the Early Years, audiovisual method, cinema, moral value. 


\section{Introducción}

La preocupación sobre la necesidad de introducir la educación en valores en el aula no ha surgido recientemente. Ya hace más de treinta años, tras la aprobación de la Ley de Ordenación General del Sistema Educativo Español en 1990, Ortega y Mínguez escribían, al hilo de la nueva propuesta legislativa, que la vieja idea de una escuela competitiva, fuertemente vinculada al éxito académico iba dando paso, aunque lentamente, a otra donde los valores, actitudes y comportamientos morales constituían objetivos básicos en el sistema educativo (Ortega y Mínguez, 1993). La escuela empezaba a concebirse como un lugar donde no sólo se enseñaban conocimientos, sino que además se aprendía a convivir, a respetar a los otros, a ser tolerante, a formarse como buen ciudadano (Ortega, Mïnguez y Gil, 1996). Dichos autores hablaban, sin duda, de la introducción explícita de una educación en valores democráticos como objetivo central del currículum en España. Ahora bien, ¿se trasladó ese avance legislativo a una renovación de la formación del profesorado destinada a procurarle las herramientas y estrategias adecuadas para una correcta educación en valores en todas las etapas del sistema educativo? A nuestro entender, no se hizo y aún queda un largo camino por recorrer en este campo. Este trabajo pretende contribuir a ofrecer algunos recursos a los docentes, en concreto a los de la etapa de infantil, tomando como elemento motivador para el alumnado el visionado de ciertos cortos de animación en los que se promueven valores democráticos. Presentamos una experiencia pedagógica realizada en un colegio público del municipio de Sevilla en la que se utilizó el cortometraje "El puente". Fue llevada a cabo durante el año académico 2014-2015, con alumnado del último curso de la etapa de infantil, es decir, con edades comprendidas entre los 5 y los 6 años. Nuestra intención es ofrecer ideas y sugerencias, para que, con las adaptaciones oportunas, se utilicen los cortometrajes como recurso didáctico destinado a trabajar la educación en valores en los centros escolares ya que es un elemento altamente atractivo para el alumnado y fomenta la participación e implicación de éste en las actividades propuestas para el logro de los objetivos en el terreno de la educación moral.

Cuando hablamos de educación en valores, nos referimos a aquella que "permite aprender, construir y estimar valores que hacen que seamos más libres e iguales entre nosotros, practiquemos estilos de vida basados en el respeto y la responsabilidad y contribuyamos a hacer más digna la vida de todos" (Martínez, 2011, p. 15). Si bien es cierto que es imposible entender una educación sin valores, hay que reconocer que desde la constitución de nuestro país como Estado social y democrático de derecho se ha hecho un notable esfuerzo dentro de la legislación educativa por promover desde las aulas los valores que asientan una sociedad democrática. Ya en la Ley Orgánica 8/1985, de 3 de julio, reguladora del Derecho a la Educación se puede leer la apuesta por valores como la paz, la cooperación o la solidaridad, la cual continúa en la primera ley general de educación promulgada en democracia, la Ley de Ordenación General del Sistema Educativo Español, (LOGSE) de 1990 y en todas las posteriores. Dado el ámbito de nuestro trabajo queremos subrayar que, concretamente en educación infantil, la Ley Orgánica para la Mejora de la Calidad Educativa (2013), que mantiene lo legislado para dicha etapa por la Ley Orgánica de Educación de 2006, propone dos objetivos directamente relacionados con la educación en valores para niños y niñas entre tres y seis años: a) Desarrollar sus capacidades afectivas y b) Relacionarse con los demás y adquirir progresivamente pautas elementales de convivencia y relación social, así como ejercitarse en la resolución pacífica de conflictos.

Si la legislación en apoyo de una educación en y para los valores democráticos es importante, no es condición suficiente para una correcta formación ética del alumnado. Es imprescindible una adecuada preparación del profesorado que responda a ciertos principios metodológicos y que proporcione estrategias para su experimentación e interiorización por 
parte de los menores. Autores como Hernando señalan que se deberá promover una metodología que no se circunscriba a facilitar unos conocimientos específicos, sino que esté orientada a formar personas, a transmitir una cultura humana, a crear actitudes de solidaridad y a plantear objetivos de perfeccionamiento individual y social (Hernando, 2002). Y en consonancia propone los siguientes principios metodológicos:

- Los valores deben estar adaptados al desarrollo evolutivo del alumnado.

- Las actividades y recursos deben permitir al educando conocer, identificar y vivir aquellos valores programados, siempre teniendo el discente el papel activo y el docente el pasivo. Eso no significa que este último no cuide su papel, puesto que deberá tener comportamientos que sirvan de ejemplo.

- El profesorado deberá propiciar situaciones naturales que permitan al niño enfrentarse a los valores y poner a prueba su capacidad para diferenciarlos.

Cabe comentar, con respecto al primer apartado, que desde las posiciones constructivistas del desarrollo se defiende una secuencia evolutiva en el crecimiento moral que se suele describir en tres amplias etapas: primera infancia, desde el nacimiento a los seis años de edad; segunda infancia, de seis a doce años; y adolescencia, desde los doce hasta los dieciocho años (Padilla, 1992). Por ejemplo, en la primera infancia, en la que hemos centrado nuestra propuesta didáctica, la heteronomía es la característica más generalizada de la moralidad, según la denominación de Piaget (1932). Dentro de dicha moral, también llamada "moral del respeto unilateral" o "moral de la obediencia", el infante respeta las reglas impuestas por la persona adulta creyendo que son absolutas, inflexibles y que, por tanto, no admiten modificación. Valora los actos en función de la conformidad material con las reglas establecidas, no de la intención que los ha originado. Kohlberg añade que, en esta etapa, que entra dentro de lo que él llama "nivel preconvencional", lo bueno y lo malo es considerado en función de las consecuencias físicas (castigo, premio, intercambio de favores) o del poder físico de los que dictaminan las reglas, siendo el control de la conducta externo al individuo (Kohlberg, 1982).

Los principios metodológicos citados se deben aplicar a diversas estrategias directamente pensadas para el ámbito de la educación moral, como la discusión y reflexión en gran grupo, ejercicios autoexpresivos, prácticas de experiencias vivenciales, representación o dramatización de situaciones específicas, simulación de soluciones de conflictos, etc. (Acosta y Páez, 2007). Entre ellas, también se encuentra el análisis de películas en las que se observen fácilmente la puesta en juego de determinados valores. Será esta estrategia la que contemplemos en este trabajo a través de la práctica realizada con alumnado de la etapa de infantil, en concreto con el cortometraje de animación titulado "El puente" (2010). Dicho corto fue realizado por Ting Chian Tey y nos cuenta en forma de fábula cómo debemos sobrepasar los obstáculos que se nos presenten en la vida. Al igual que las clásicas fábulas de Samaniego y Esopo, sus protagonistas son animales, en este caso cuatro, que intentan cruzar el puente. Ahora bien, no es fácil pues el puente es muy estrecho y unos se estorban a otros para el logro del objetivo. El cortometraje propone un caso de resolución de conflictos y le presenta a los espectadores una solución a través de la cooperación, en lugar de mediante la confrontación y la violencia.

¿Por qué utilizar el cine como herramienta de educación en valores? Este siglo XXI viene marcado, entre otras cosas, por la constitución de una sociedad mediática donde todas las facetas de los individuos (social, política, etc.) se encuentran influenciadas por la misma. Los mass-media se convierten en un potente agente educativo para la infancia, compitiendo duramente con otros agentes tradicionales como la familia y la escuela. La presencia diaria de los medios de comunicación de masas en sus vidas, unida a su poder de atracción, posibilita 
que puedan ser un instrumento educativo de primera categoría. Dentro de estos medios, la televisión -especialmente a través de los dibujos animados que emite- es el agente más cercano y más utilizado en las primeras edades. Por este motivo, consideramos que una buena selección de contenidos audiovisuales tiene la fuerza suficiente para convertirse en un verdadero recurso pedagógico que contribuya a la iniciación de nuevos lenguajes, comprender mejor, aspectos de la vida y acercar conceptos y valores difíciles de comprender por otros medios educativos (Pérez, 2010).

El cine, al que se ha llamado "el Séptimo Arte", es un medio de comunicación social que refleja la sociedad en la que vivimos, siendo capaz de configurar modelos de actuación, especialmente entre el público más joven. En efecto, desde sus orígenes, hace más de cien años, el cine ha actuado en la trasmisión de valores, patrones y conductas, configurando la personalidad e identidad de los miembros de la sociedad, especialmente de la población infantil (Ambrós y Breu, 2007). Esta es una franja de individuos que se encuentran en pleno proceso de desarrollo de las diferentes dimensiones de la personalidad y aún carecen de madurez crítica y cognitiva. No obstante, poseen gran capacidad para absorber los diferentes mensajes, estilos y modelos culturales que exhiben las pantallas, así como para incorporarlas a sus esquemas/patrones conductuales y emocionales. Desde el nacimiento, los seres humanos comienzan el proceso de aprendizaje del entorno, principalmente a través de dos mecanismos: observación e imitación. Este último perdurará a lo largo de toda la vida, pero, a medida que avancen en edad, los sujetos comenzarán a imitar sólo aquellas conductas y patrones que les susciten algún tipo de interés o afinidad. Durante la etapa de Educación Infantil (3-6 años), y relacionando lo dicho con el cine como agente socializador, los menores comienzan a reproducir consciente o inconscientemente acciones, valores y conductas de sus héroes y heroínas cinematográficos favoritos. De este modo, el cine se convierte en estos primeros años de vida, en un canal de transmisión cercano y atractivo, es decir, en un instrumento óptimo para el intercambio de conocimientos, ideas, actitudes y valores educativos (Bonilla, Loscertales y Páez, 2012).

El cine constituye un elemento clave en el ámbito educativo porque su misión no se limita únicamente a entretener o divertir. Su capacidad de influencia traspasa los diversos elementos del currículo a la vez que invita "a la modificación de conductas o a la identificación con valores apreciados" (Pereira, 2009, p. 27). El cine infantil fue creado como una herramienta pedagógica para transmitir moralejas y valores, especialmente de convivencia, a un público infantil (Sánchez, 2009). Con el paso de los años y la llegada de las diversas compañías productoras, ese primitivo objetivo cambió por completo. Actualmente, los menores conviven con una gran variedad de comportamientos, conductas y valores emitidos de manera constante y variada por las diferentes películas infantiles. En algunos casos, todos estos aspectos contribuyen a un óptimo desarrollo moral-afectivo y una adecuada convivencia en sociedad. En cambio, en otras ocasiones, el papel cambia y la influencia de los elementos cinematográficos (música, sonidos, imágenes) es negativa tanto a nivel individual como colectivo, propiciando conductas no respetuosas, insolidarias, violentas, etc. Este aspecto, en parte, explica que en nuestros días el cine necesite de una intervención educativa para convertirse en una fuente de aprendizaje positiva.

Guichot y Rueda (2010) sintetizan algunas ventajas del cine como recurso educativo y señalan tres: aprendizaje duradero, atracción para el alumnado e interdisciplinariedad. En cuanto al primero, se refieren al hecho de que, si se usa imágenes y sonidos que reflejen de un modo fiel la realidad que queremos estudiar, el recuerdo de los mismos permanece largo tiempo en la memoria. El clásico dicho de que "una imagen vale más de mil palabras" se fundamenta en los resultados de diversas investigaciones relacionadas con los procesos memorísticos mediante imágenes y sonido. Un individuo con unos resultados de tests de 
memoria localizados en el centro de la curva normal, estadísticamente hablando, recuerda aproximadamente el sesenta por ciento de las cosas que se almacenan en el intelecto como imagen con sonido, un treinta por ciento de lo que únicamente ve y un quince por ciento de algo que sólo oye. El cine se ubica dentro del primer tramo, imágenes y sonido; por consiguiente, algunas escenas de películas son elementos de recuerdos de significativa permanencia.

En cuanto al segundo factor citado, la atracción para el alumnado, no podemos dejar atrás que, actualmente, muchos niños y jóvenes dedican parte de su tiempo libre a ver sus películas favoritas. El lenguaje cinematográfico, donde se mezclan conversaciones de los personajes, con pensamientos, música, imagen, en tiempos y espacios propios, logra seducir al espectador, justo lo que el profesorado desea obtener en clase cuando desarrolla algún tema, la captación del interés. MacLuhan, además, insiste en el hecho de que el cine posibilita aumentar las capacidades de las personas tanto mediante la reconstrucción del conocimiento como del posterior contraste de la información expuesta con las situaciones habituales en la realidad del espectador. Y hace hincapié en el importante carácter motivador del cine, similar al presente en algunas de las nuevas tecnologías informáticas, que ayudan al aprendizaje de las personas (MacLuhan, 1996). La excitación de los sentidos de forma conjunta, el impacto de la imagen, la energía de la historia contada, la música del film, la identificación con los personajes... permiten un proceso de enseñanza menos complejo y más centrado en el discente que en las explicaciones del profesorado.

Por último, es incuestionable que en la comunicación cinematográfica entra en juego la interdisciplinariedad. Entre los campos que influyen -y también son afectados por el cinehallamos las ciencias que tocan la realidad social, tales como la psicología, la sociología, la filosofía o la antropología. Este efecto de integración de saberes facilita acceder al conocimiento de la sociedad entendida en su totalidad.

Sin embargo, no podemos olvidar que, como afirma Martínez-Salanova (2003), el cine, para que incida en la cultura y por tanto sea un canal de transmisión de valores, no sólo debe quedarse en el visionado, sino que requiere un trabajo posterior al mismo. Tomando como referencia estas aportaciones, tenemos que afirmar que la educación en valores a través del cine requiere de esfuerzo y trabajo por parte de los profesionales de la educación. Los resultados que se obtengan se encuentran ligados a la labor que realicen los mismos. El objetivo de lograr ciudadanos completos y desarrollados integralmente va mucho más allá del visionado de la película. La experiencia que presentamos implica todo un planteamiento didáctico que posibilita el desarrollo de objetivos educativos deseables. Para conseguirlos, se han tenido en cuenta aspectos como:

- Seleccionar un cortometraje que aborde los valores y conductas que deseamos eliminar y/o potenciar. Asimismo, éste debe ser adecuado al nivel de desarrollo del alumnado al que se dirige, lo que significa que se debe tener en cuenta tanto la duración como el nivel de lenguaje.

- Analizar los posibles valores y conductas que se emiten en la misma.

- Programar y considerar diversas intervenciones teniendo como recurso principal el cortometraje seleccionado. Se deben realizar unas actividades tanto previas como posteriores al visionado del filme. En el caso de las previas, el trabajo estará orientado a la preparación del espacio y el tiempo. En cambio, en las posteriores se analizará y se hará hincapié en la transmisión de los valores que queremos que el alumnado interiorice. Para el logro de dicha interiorización de un modo óptimo y duradero, los estudiantes han de ser participantes activos. Algunas estrategias que se pueden 
emplear son las preguntas de comprensión, la identificación de situaciones similares en la vida real, los juegos de roles, los guiones imaginarios o el cambio de finales.

En definitiva, como indican Correyero y Melgarejo (2010), el cine tiene la extraordinaria capacidad de modelar las raíces culturales, pues los elementos que lo componen contienen siempre algunos valores propios de la sociedad. La cercanía que tiene este medio para el público infantil permite que la ficción se haga realidad a la vez que facilite el aprendizaje de los diferentes contenidos necesarios para la vida en sociedad.

\section{Una propuesta educativa para educar en valores en la etapa de educación infantil mediante el cortometraje "El puente"}

Exponemos a continuación la ficha de trabajo, de elaboración propia, que se le facilitará al profesorado de educación infantil para educar en valores a través del cortometraje de animación "El puente" (2010), dirigido por Ting Chian Tey. Entre los elementos que nos llevaron a elegir dicho corto se encuentran:

- Posee gran potencial para la educación en valores (valores como la empatía, la cooperación, se presentan en el filme)

- La presentación de dichos valores es adecuada para el nivel cognitivo de la población infantil. Además, los personajes son animales, seres muy cercanos y apreciados en la infancia.

- Breve duración, que impide que el alumnado de estas edades se canse o pierda el hilo de la trama.

- El alumnado no se puede perder en la comprensión del diálogo verbal de los personajes porque es muda y son gestos y posturas lo que constituye la forma de comunicación.

CORTOMETRAJE: EL PUENTE (TING CHIAN TEY, 2010)

\section{Sinopsis:}

Un oso y un reno intentan cruzar simultáneamente un puente muy estrecho que sólo posee espacio para el paso de un individuo. Cuando ambos llegan a la mitad del recorrido del puente, se encuentran cara a cara y observan que no pueden pasar al mismo tiempo. El oso señala al reno el camino de vuelta para que retroceda y pueda pasar él. Éste se niega y surge una disputa. Mientras ocurre esto, un tercer animal, un mapache, les indica que él también quiere pasar, pero el oso, de gran tamaño, se niega y lanza al mapache al principio del puente de una patada. Esta escena se vuelve a repetir pero teniendo como protagonista a un conejito. Finalmente, los dos pequeños animalillos -mapache y conejo- deciden cortar y desatar las cuerdas del puente para que el oso y el reno caigan y ellos poder cruzar. Sin embargo, al llegar a la mitad del camino se encuentran con el mismo problema. En esta ocasión, ellos se ponen de acuerdo, buscan una solución que a ambos beneficia, y consiguen llegar al extremo opuesto.

\section{Objetivos:}

- Adquirir valores morales como el respeto hacia el otro y la cooperación de forma lúdica.

- Valorar la importancia del diálogo en nuestras vidas, sobre todo como medio de resolución de conflictos.

- Conocer estrategias para resolver los conflictos de forma pacífica.

- Desarrollar la empatía hacia los demás.

- Favorecer el trabajo en equipo y la ayuda mutua.

- Eliminar comportamientos negativos como las conductas egoístas y las autoritarias. 


\begin{tabular}{|l|l|}
\hline \multicolumn{1}{|c|}{ Valores que favorece: } & \multicolumn{1}{c}{ Contravalores que intenta eliminar } \\
- El diálogo. & - El egoísmo. \\
- El trabajo en equipo. & - La ausencia del diálogo. \\
- La cooperación. & - La imposición del propio parecer a los demás. \\
- El respeto. & - La violencia \\
- La paciencia. & \\
\hline \multicolumn{2}{|c}{} \\
\hline
\end{tabular}

Antes de la visualización del cortometraje:

La actividad previa estará enfocada a preparar el clima y el espacio físico donde se desarrollará la propuesta. Para conseguir una propuesta óptima, se deberán tener en cuenta las siguientes condiciones:

- Seleccionar un momento idóneo de tranquilidad. Por tanto, el aula deberá estar libre de ruidos y objetos que fomenten la distracción.

- La disposición del proyector/televisor deberá ser adecuada, de tal manera que todo el alumnado pueda visualizar fácilmente la proyección. Igualmente, la distribución de las sillas habrá de ser dispuesta de acuerdo al tipo de actividad.

- La cantidad de luz deberá ser regulada. En el caso de tratarse de luz natural se cerrarán las persianas, mientras que, si es luz eléctrica, ésta se apagará.

- Se creará en cada una de las fases, un ambiente cálido y cercano para que los discentes estén dispuestos a participar.

\section{Visionado:}

Se realizará de manera continuada, sin interrupciones, y bajo las condiciones comentadas anteriormente.

\section{Después de la proyección:}

Se recogen distintos tipos de actividades:

Actividades de comprensión: Se basarán en preguntas destinadas a los discentes para corroborar que han entendido aspectos como:

- ¿Cuántos personajes aparecen en el filme?

- ¿Qué animales son esos personajes? ¿Qué características tienen (tamaño, colores...)?

- ¿Qué quieren hacer los cuatro animales?

- Para conseguir cruzar el puente, ¿qué hacen el reno y el oso?, ¿y el conejo y el mapache?

- ¿Todos los animales consiguen lo que querían, cruzar el puente? ¿por qué algunos no lo logran?

- ¿Qué personaje te gusta más?, ¿Por qué?

- ¿Cómo qué animal te gustaría cruzar el puente?, ¿Por qué?

Actividades de creatividad: Se presentan algunos ejercicios que tienen como eje en común la puesta en práctica de la creatividad. A través de ésta y la imaginación, los menores podrán resolver las actividades a la vez que trabajan los valores.

- Durante un minuto se pondrá un fragmento del cortometraje y se le quitará el audio (música instrumental del corto). En ese momento pediremos a los discentes que nos proporcionen un diálogo para los personajes según las escenas que vayan ocurriendo.

- Cada estudiante modelará con plastilina el animal que más le gusta, debido a la forma en la que ha conseguido cruzar el puente. 
- Se colocará al alumnado por parejas y a cada una de ellas se les repartirá la lámina que contendrá las tarjetas para jugar al juego de memorizar parejas. Estas tarjetas se componen de cuatro dúos de animales que realizan acciones que plasman valores. Cada pareja coloreará las tarjetas, las recortará y finalmente, jugará con ellas.

Actividades de resolución de conflictos: En esta ocasión se pretende trabajar los valores señalados mediante actividades que requieren de diversas formas de resolver una situación para llegar al fin del ejercicio.

- En la pizarra, de manera grupal, se completarán dos de los tres cuadrados que componen el esquema. La solución que cada menor le hubiese dado, se realizará de manera individual y posteriormente, habrá una puesta en común de estas respuestas individuales.

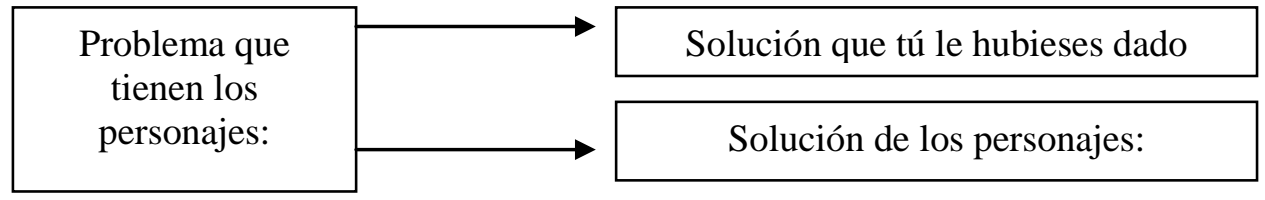

- En esta actividad simularemos la escena del corto. Para ello dos participantes se montarán encima de un banco sueco, cada uno por un extremo, con el objetivo de llegar hasta el extremo opuesto.

- Entre todo el grupo se creará un semáforo donde se colocarán a los cuatro personajes. En un primer momento, unos alumnos se encargarán de la realización del semáforo mientras que el resto coloreará y recortará los personajes. Finalizadas ambas partes, se colocarán a los personajes en el lugar correspondiente: al oso y al reno en la luz roja junto a la expresión "ausencia de diálogo"; al conejo y el mapache, en la verde bajo el rótulo "diálogo".

- La clase se dividirá en cuatro grupos y a cada uno se le asignará una fotografía de un animal del filme. Entre los componentes del equipo deberán describir cómo es físicamente el personaje, si está enfadado o alegre, si usa el diálogo o la fuerza para resolver el conflicto, qué cosas les gustan de ese animal y cuáles no. Finalizada la descripción, será presentada por cada equipo.

- Se dibujará una raya en el suelo, simulando el puente. La clase se dividirá en dos equipos y se colocarán detrás de los extremos de la línea. El objetivo del juego es que los dos equipos consigan meter las pelotas del color asignado en un cesto. Dicho cesto se colocará en el equipo opuesto, es decir, detrás del equipo A estará el cesto B que deberá contener las pelotas del equipo B y viceversa. Para el desarrollo de la actividad, tendrán que avanzar para depositar las pelotas desde su extremo hasta el opuesto, cogidas las manos, sin soltarse y por encima de la línea. Ganará quien consiga meter más pelotas en su cesto asignado.

\section{Recursos:}

Pelotas de dos s diferentes, plastilina, ceras de diferentes colores, dibujos de los personajes, plantilla de las tarjetas del juego de memorizar parejas, cartón, témperas, pinceles, pegamento y tijeras.

\section{Metodología:}

Será activa por parte del alumnado. Todos, independientemente de sus características, podrán construir, según sus posibilidades, su propio aprendizaje. El docente debe ejercer de coordinador, buscando que el alumnado sea el protagonista de las actividades. El profesorado deberá estar siempre disponible para atender las posibles dudas o problemas que pudiesen surgir en el proceso. Los contenidos no se trabajarán de manera aislada, sino que estarán en coordinación con los del resto de áreas de aprendizaje. Por lo tanto, se apostará por una metodología activa, interdisciplinar y relacionada con el entorno de los pequeños.

\section{Evaluación:}

La evaluación se enfocará para comprobar el nivel de adquisición de los objetivos programados y los resultados en el proceso enseñanza- aprendizaje. Ahora bien, hay que considerar que la propuesta servirá para reforzar los valores indicados, ya que no será la única vez donde se trabajen estos, sino que se hará desde principio de curso a través de diferentes propuestas basadas en otros cortometrajes, cuentos, teatros... y con actividades similares a que aquí desarrollamos.

La evaluación deberá ser global, continua y formativa. Para ello, se utilizarán como principales técnicas de 
evaluación: la observación directa y sistemática, junto a las producciones diseñadas en cada actividad por parte del alumnado.

\section{Observaciones:}

En esta ocasión, por falta de tiempo, se ha planteado una propuesta para trabajar el ámbito de los valores y su exteriorización en los comportamientos de forma aislada y sin relación con alguna unidad didáctica o proyecto. A pesar de ser así, la metodología que debe predominar en Educación Infantil debe responder a los principios de integración, globalidad e interdisciplinariedad. Esto significa que verdaderamente el supuesto planteado debería de ir mucho más allá del ámbito abordado y se deberían trabajar mediante el mismo, los diferentes bloques de cada área educativa. De este modo, encontramos que tomando la propuesta como actividad inicial y como hilo conductor para desarrollar una unidad didáctica completa, este cortometraje ayudaría a abordar contenidos matemáticos, por ejemplo, contando el número de personajes o las partes del cuerpo de los mismos. Igualmente facilita el acercamiento al mundo de la alimentación, la naturaleza, las artes plásticas, los colores, la música, la psicomotricidad, etc.

En cuanto al desarrollo de esta propuesta, algunas actividades han sido llevadas a la práctica en un aula de cinco años (tercero de infantil, segundo ciclo) de un colegio público ubicado en el municipio de Sevilla capital que cuenta con dos etapas, infantil y primaria, durante el curso académico 2014-2015. El número de niños y niñas que han participado en la práctica con este cortometraje han sido veinte, de los cuales nueve eran niñas y once niños. Los docentes implicados han sido dos: la tutora del aula y una alumna en prácticas del grado de educación infantil.

Para la puesta en práctica se tuvieron en cuenta todas las recomendaciones citadas anteriormente para crear un ambiente cálido y acogedor, además de libre de ruidos, que facilitase la buena realización de toda la experiencia. Se pudo detectar desde el primer momento que el alumnado, tanto por sus intervenciones verbales como por sus gestos, miradas y posturas, estaba expectante ante algo que le resultaba novedoso, más aún cuando "entraba una persona nueva" en el aula acompañando a su maestra habitual.

Una vez que se pasó el cortometraje, el propio alumnado pidió repetir la visualización, algo que no es de extrañar dada la edad de los pequeños. Eso les permitió fijarse más detalladamente en algunos aspectos que, probablemente, pudieron pasar más desapercibidos la primera vez y mejorar su comprensión. Se evidenció la atención que prestaban al ver el filme a través de risas y comentarios que provocaban las situaciones que se desarrollaban en el mismo.

Tras el visionado, se empezaron a desarrollar las actividades de comprensión. Se pudo observar el alto grado de participación, pues todos querían dar su respuesta, algo que también indica que se habían implicado en la tarea y que se sentían a gusto con lo ofrecido. Cabe señalar que había existido una buena comprensión en general del cortometraje, y sólo en algunos casos en los que se detectó errores en algunas intervenciones del alumnado, se visualizó de nuevo la escena en la que se desarrollaba el contenido de la pregunta para determinar qué respuesta era la correcta. A través de sus contestaciones y sus explicaciones, se apreciaba la simpatía por los animales que se comportaban de modo adecuado para resolver el problema, aquellos que no utilizaban la violencia, y que los estudiantes sabían que no se debe agredir al otro ni emplear métodos violentos para conseguir los objetivos.

Se iniciaron posteriormente las actividades de creatividad, en las que niños y niñas tenían que trabajar las diferentes siluetas que conforman el juego de memorizar deduciendo y debatiendo que ocurre en cada pareja de animales (según lo que ha ocurrido en el filme). Posteriormente, jugaron en parejas con lo que se facilitó la interacción a la hora de la resolución de conflictos 
Asimismo, se quería observar si los discentes habían interiorizado bien cómo se deben afrontar soluciones de conflicto como la presentada por el filme. Para ello, cuatro voluntarios realizaron libremente un pequeño diálogo para ponerle voz a las escenas del corto. De este modo, pretendíamos apreciar qué tipo de lenguaje asociaban a los gestos y posturas de los animales. Observamos que, en efecto, reconocían la expresión de las emociones básicas como la ira o enfado, la alegría, el miedo y la tristeza. Entre todas las frases que componían la conversación entre los animales del cortometraje, la negación "no" y "estoy muy enfadado" son las dos expresiones de carácter negativo más utilizado para el reno y el oso, según el propio alumnado. En cambio, los otros dos animales llegan a un acuerdo a través de "me dejas pasar", "sí", "somos amigos" y "gracias" (en palabras de los discentes). Eso nos hizo propiciar una reflexión acerca de cómo se deben hacer las peticiones, cómo se ha de agradecer un favor, la importancia de llevarse bien con los otros, etc.

Otro bloque de actividades se encaminó directamente a la resolución de conflictos, que se enlazaba claramente con lo que se acababa de realizar. Entre todo el grupo se hizo un esquema en la pizarra para encontrar posibles soluciones a lo ocurrido en el corto. Hubo consenso en que el problema era el intento por parte de los personajes de querer pasar a la vez por un puente que es muy estrecho, lo que es imposible. Como solución, mientras dos animales eligen pelearse, los otros dos restantes se ponen de acuerdo. Finalmente, el alumnado señala que las soluciones que ellos hubieran tomado serían: ser amigos y permitir que pasara primero uno y después otro y/o volver atrás y echar a suerte quien pasaba primero. Queremos comentar que ambas son soluciones pacíficas.

Se propuso entonces lo que llamamos "el semáforo del diálogo", actividad en la que los menores se reunían en pequeños grupos de trabajo para hacerlo. Antes de iniciar la elaboración, se les preguntó sobre la actitud de los personajes y la utilización o no del diálogo. Posteriormente, los grupos colocaron a los personajes según su actitud en la luz roja o en la luz verde del semáforo. Todos los grupos supieron poner en la luz roja de "prohibido" al oso y al reno, y en la verde a los dos pequeños animalillos.

\section{Conclusiones}

La puesta en práctica de estas actividades, que giran en torno a la visualización de un corto, ha permitido alcanzar los objetivos propuestos, a la vez que ha posibilitado intervenciones para conseguir tanto la eliminación de contravalores (egoísmo, imposición del parecer) como la potenciación de algunos de los valores (el diálogo, el trabajo en equipo, el respeto activo) que programamos al diseñar la actividad. Con el desarrollo de las diversas actividades, se han realizado observaciones importantes, como que los estudiantes suelen hablar de los personajes aludiendo a sus rasgos físicos (por ejemplo, afirmaban que los más grandes eran más malos que los más pequeños). Asimismo, encontramos que el alumnado que ha participado no ha identificado claramente los valores, pero sí los ha sabido asociar a cada personaje, de tal modo que los personajes que hacen uso de los contravalores son señalados por los niños como personajes que menos les gusta, mientras que aquellos que ejercen valores positivos como el diálogo o la cooperación, son los preferidos por el público infantil.

Sin duda, los valores están presentes en nuestras vidas desde que nacemos, jugando un papel importante en el desarrollo de la personalidad, y deberían contribuir a convertirnos en una ciudadanía con las cualidades y recursos necesarios para vivir en una sociedad plural. Éstos son adquiridos mediante diversos agentes socializadores, siendo el ámbito escolar un medio de proporcionar situaciones de aprendizaje de gran importancia para adquirir los valores básicos para la integración en el entorno. Con esta experiencia comprobamos que este cortometraje está cargado de valores y contravalores que posibilitan enseñar y modelar 
comportamientos sociales. Los cortometrajes tienen, para los más pequeños, un fuerte carácter motivador, siempre que se realice una adecuada selección por parte de los educadores, y facilita la empatía, ese ponerse en el lugar del otro, que nos ayuda a comprender las razones y sentimientos que mueven a los demás a actuar. Por lo tanto, creemos que debe ser un recurso de enseñanza que debiera ser más utilizado en las aulas de Educación Infantil como un mecanismo privilegiado para trabajar no sólo la Educación en Valores, sino cada una de los ámbitos de aprendizaje que recoge la Orden 5 de Agosto del 2008 para esta etapa educativa.

Desde este trabajo, queremos alentar al profesorado universitario que imparte docencia a los futuros maestros y maestras de educación infantil de la importancia de formar en el uso del cine como instrumento didáctico. Asimismo, deseamos animar a aquellos que ya son profesionales en ejercicio en esta etapa a que, si no se sienten bien capacitados para su uso, busquen lugar, dentro de esa formación permanente, deber para todo educador, para conocer las enormes potencialidades que ofrece el cine en la educación. El profesorado ha de reflexionar constantemente sobre su actuación docente, pues es la única vía para poder saber si se está fomentando en el alumnado aquello que se quiere que aprenda y, por consiguiente, poder renovar de algún modo su enseñanza, contribuyendo siempre al que ha de ser el fin último de ésta, la mejora del aprendizaje del alumnado (Navarro, 2015).

\section{Referencias bibliográficas}

Acosta, M., y Páez, H. (2007). Estrategias didácticas para Educar en Valores. 10 valores con intencionalidad. Revista Educación en Valores, 2 (8). 57-69. Recuperado de: http://servicio.bc.uc.edu.ve/multidisciplinarias/educacion-en-valores/v2n8/art9.pdf

Ambrós, A., y Breu, R. (2007). Cine y educación. El cine en el aula de primaria y secundaria. Barcelona: Graò.

Bergala, A. (2007). La hipótesis del cine: pequeño tratado sobre transformación del cine en la escuela y fuera de ella. Barcelona: Leartes

Bonilla, J., Loscertales, F., y Páez, Ma . M. (2012). La Educación en Valores a través del cine. Píxel-Bit. Revista de Medios y Educación, (41), 117-131. Recuperado de: http://acdc.sav.us.es/pixelbit/images/stories/p41/09.pdf

Correyero, B. y Melgarejo. I. (2010). Cine, música y valores: de Blancanieves a Tiana. 19pp Recuperado http://www.gabinetecomunicacionyeducacion.com/sites/default/files/field/adjuntos/ci ne_musica_y_valores_de_blancanieves_a_tiana.pdf

De la Torre, S. y otros (2005). El cine, un entorno educativo. Madrid: Narcea.

Gómez García, M. N. (2006). El aula escolar, escenario, narración y metáfora: Nuevas Fuentes para la Historia de la Educación. Revista Interuniversitaria de Historia de la Educación, 25, 341-358.

Guichot-Reina, V. y Rueda Andrade, J. D. (2010). El cine como mirada a nuestro pasado educativo reciente: "Los días del pasado", recurso para analizar la educación en el periodo franquista", Cuadernos de Historia de la Educación. Monográfico: El cine como recurso metodológico en la docencia de Historia de la Educación (7), 39-70. 
Hernando, Ma . A. (2002). Estrategias para educar en valores. Madrid: Editorial CCS.

Kohlberg, L. (1982). Estadios morales y moralización. El enfoque cognitivo-evolutivo. Infancia y Aprendizaje, (18), 33-51.

Martínez, M. (2011). Educación, Valores y Democracia. Revista de Educación, número extraordinario, 15-19. Recuperado de: http://www.revistaeducacion.mec.es/re2011/re2011_01.pdf

Martínez-Salanova, E. (2003). El valor del cine para aprender y enseñar. Revista Científica de Comunicación y Educación, 20, 45-52. Recuperado de: http://www.revistacomunicar.com/index.php?contenido=detalles\&numero=20\&artic ulo $=20-2003-07$

Navarro Granados, M. (2015). Hacia una educación en valores que responda a los retos de la sociedad actual: el caso del CEIP Juan Ramón Jiménez. Cuestiones pedagógicas (24), 11-24.

Ortega, P., y Mínguez, R. (1993). Educación intercultural y democracia. En P. Ortega., y J., Sáez (eds). Educación y democracia. Murcia: Cajamurcia.

Ortega, P., Mínguez, R. y Gil, R. (1996). La tolerancia en la escuela. Barcelona: Ariel.

Padilla, M ${ }^{a}$ L. (1993). La construcción de los valores morales: un tema de especial interés para el desarrollo y la educación humana. Cuestiones pedagógicas (10-11), 173-200.

Pérez Millán, J.A. (2014). Cine, enseñanza y enseñanza del cine: de la autodefensa al disfrute. Madrid: Morata.

Pereira, Ma . C. (2009). El valor social del cine en la infancia. En M. Raposo (coord.). El cine en educación: realidades y propuestas para su utilización en el aula (pp.17-38). A Coruña: Tórculo Artes Gráficas.

Pérez, M. (2010). El cine como recurso educativo. Revista Digital Innovación y experiencias educativas, (30). 10 pp. Recuperado de: http://www.csicsif.es/andalucia/modules/mod_ense/revista/pdf/Numero_30/MARIA_C_PEREZ_1. pdf

Piaget, J. (1932). Le jugement moral chez l’enfant. París: Alcan. Trad. Cast.: El criterio moral en el niño. Barcelona: Fontanella, 1971.

Ruiz Rubio, F. (1994). Cine y enseñanza. Comunicar, 3, 74-80.

Sánchez, A.B. (2009). El cine / cuento animado o la ruptura del modelo clásico. Área abierta, (24). Recuperado de: http://revistas.ucm.es/index.php/arab/article/view/arab0909330001c

\section{Legislación:}

Ley Orgánica 8/1985, de 3 de julio, reguladora del Derecho a la Educación (Boletín Oficial del Estado, 159, 4 de julio de 1985). 
Ley Orgánica 1/1990, de 3 de octubre de 1990, de Ordenación General del Sistema Educativo (Boletín Oficial del Estado, 238, 4 de octubre de 1990).

Ley Orgánica 2/2006, de 3 de mayo, de Educación (Boletín Oficial del Estado, 106, 4 de mayo de 2006).

Ley Orgánica 8/2013 de 9 de diciembre, para la Mejora de la Calidad Educativa, (Boletín Oficial del Estado, 295, 10 diciembre de 2013).

Orden 5 de agosto del 2008 por la que se desarrolla el Currículo correspondiente a la Educación Infantil en Andalucía (BOJA, 169, de 26 de Agosto de 2008).

\section{Webs sobre cine y educación}

http://www.uhu.es/cine.educacion

http://www.auladecine.com/

http://www.aulamedia.org/

http://www.cineescola.info/ 
